(Eds.), Mockers and the mocked. Comparative perspectives on differentiation, convergence and diversity in higher education ( $\mathrm{pp} .42-58$ ). London: Jessica Kingsley.

Van Vught, F. (2008). Mission diversity and reputation in higher education. Higher Education Policy, $21(1)$ 151-174

Van Vught. F. (Ed.). (1989). Governmental strategies and innovation in higher education. London: Jessica Kingsley.

Jessica Kingsley. Witte, J. (2006). Change of degrees and degrees of change. Comparing adlaplat

education systems in the context of the Bologn prochs Witte, J. (2007). European and US-Amencan higher ASu ahon. The Bologna Process benteen internal and external aspirations. Paper presented at the ASHE International Forum, Louisville, Kentucky, US, 7-10 November.

Witte, J. (2008). Aspired convergence, cherished diversity: Dealing with the contradictions of Bologna Tertiary Education and Management, 14(2), 81-93.

Witte, J., \& Huisman, J. (2008). Disciplines in the Bologna process: curriculum reconstruction by German engineers. In L. Purser, L. Wilson, E. Froment \& J. Kohler (Eds.), EUA Bologna Handbook. Stuttgart: EUA/Rabe.

Witte, J Van der Wende, M \& Huisman, J (2008). Blurring boundaries: How the Bologna process , Jan changes the relation nship between university and non-university high:

Netherlands, and France. Studies). Significant figures - performance indicators and 'league tables'. London: SCOP.

\section{FEATURES AND FUTURE OF THE NETWORK SOCIETY: THE DEMOGRAPHIC, TECHNOLOGICAL AND SOCIAL CONTEXT OF HIGHER EDUCATION}

\author{
INTRODUCTION
}

The network society is an amalgam of technological, economic, political, social, and cultural developments that, taken together, form a new context for our European societies and for higher education within these societies. The idea of a netw ork society, it can be said, captures 'the spirit of our age', that is, it is an attempt to make sense of the changes of which we are in the midst of (Barney 2006).

In this chapter, we first explain Manuel Castells' theory of the network society, and then we go into some basic features of European societies that form the context in which the network society develops. More in particular, we discuss demographic, technological, and social developments. Throughout, we point out their consequen ces for higher education. Then we will discuss the European Area for Higher Education (EHEA) in the context of the network society. Finally, we will draw some conclusions regarding the future development of the EHEA in view of the network society and its basic features.

\section{THE NETWORK SOCIETY AND ITS CONSEQUENCES}

The network society, according to Castells, is the social structure of the Information Age (Castells 1996, 1997, 1998, also 2000). In the Information Age, our societies are increasingly being organized on the basis of a new technological paradigm with technical, organizational, and managerial innovations. As a result, 'dominant functions, social groups, and territories across the globe are connected' (Castells 1996: 34). The network society consists of both the technology to make all kinds of networks work and the network as an organizational form that penetrates the entire social structure. In other words, if we want to characterize our societies, the metaphor of a network, rather than that of a structure, seems to be more appropriate. A shift is taking place from national societies based on a social structure towards global flows or networks of signs, money, information, technology, and people (Lash \& Urry 1994). Of course, global flows or networks are not entirely new (indeed, trade and religion have been 'larger than national' for centuries). But a number of features make the current age stand out against earlier phases. The network society is an ideal type with particular economic, social/ cultural, and political characteristics.

The new economy is informational and global. An informational economy is based on the capacity of economic units to generate, process, and apply knowled ge.

B.M. Kehm, J. Huisman and B. Siensaker (eds.), The European Higher Education Area Perspectives on a Moving Target, 263-280.

○ 2009 Sense Publishers. All rights reserved 
It is characterized by technological innovation, organizational flexibilization, and the use of ICT-based knowledge, even in industrial production, to enhance the knowledge production itself. The dominant strategy of companies has become to seek profit rather than improve productivity. This leads them to concentrate on searching for new markets or market segments, which in turn requires better mobility and better communication. This has become possible through market deregulation and the new ICT. In this way, the key elements and processes of the economy become global: capital, the labour market, science and technology, goods and services, and management (Castells 1996: 93-96). This strategic core becomes networked on a global scale in a global economy (Castells 1996: 92; 2000: 10). Economic decisions can be made immediately, continuously, and globally by means of electronic communication. However, while capital is becoming extremely volatile, labour remains more static as it is curtailed by cultures, institutions, borders, and the like. But even with regard to labour, global interdependence is increasing as a result of the multinationals, international trade, and global competition. Labour is becoming increasingly exchangeable throughout the globe in so far as the work itself consists more and more of information processing. What the informational economy needs is 'self-programmable labour' (Castells 1996). These autonomous, trained labourers show their informational capacity in that they can lead large parts of the labour process, can constantly retrain themselves, and can continuously adapt to new tasks, new processes, and new sources of information, thereby analysing and solving problems creatively and in communication with others. On the other end of the spectrum is 'generic labour', the unqualified labourers throughout the world. Their jobs are replaceable and disposable, not unlike machines, and their only good fortune is still to be part of the network. If no longer networked, they become 'switched-off labour', (Castells 1998). In the global informational economy, successful organizations are the ones that are network organizations, that is, have new organizational forms (in production, in management, in cooperation, etc.) based on networks between organizations, within organizations, between people, and between computers (Castells 1996: 165-166).

The impact of informationalism in the social and cultural domain is defined by Castells as the emergence of a 'culture of real virtuality' (Castells 1996, 2000). Increasingly, we are living in an audio-visual multimedia environment. We see the world as a succession of electronic signs that not only represent reality but increasingly become reality. In this way, what is created is 'a multifaceted semantic context made of a random mixture of various meanings' (Castells 1996: 371). It is, in a sense, a homogenized culture. Receivers still interpret this cultural context but individually, not starting from common cultural codes, or do so to a lesser degree. This generates fragmentation but at the same time leaves room for collective actors to communicate and participate in the system, as no single actor, not even large companies or governments, can completely control this system. Unfortunately, this emancipatory power of the new system is only realized in principle because computer-mediated communication is unevenly distributed and the prosperous, the wealthy, and the skilled are far more likely to participate in it (see below) than are others.
This brings us to a third aspect of the network society, that is, power relations. Networks lack a single centre and have no clear-cut hierarchy. Networks are clusters of relations that can change in number and intensity, unbound by a fixed space or time in the interaction with changes in their environment. Networks are, therefore, at odds with territorial and hierarchical organizations such as nation states, churches, and schools (Castells 2000: 19). As far as the nation state is concerned, it loses some of its power in a network society because of the aggregation of interests and policies at a supranational level and the tendencies towards decentralization (Castells 1997). As a result, national identities are waning and new identities are being built on the basis of other cultural, ethnic, social, or geographical elements. This can lead both to a rejection of the globally networked society and a turn towards local, narrow cultures or to new forms of democracy embracing local democracy, electronically stimulated participation, and communication and political mobilization (Castells 1997).

The ideal type of the network society will take on a different form in specific societies because each society has its own history, its own culture, and its own institutions. Therefore, we will now consider some of the basic demographical, technological, and socio-cultural features of European societies.

\section{DEMOGRAPHIC CHALLENGES}

In the network society, both personal development and economic development depend on the skills and competencies of individuals. These are acquired by means of higher education. But for higher education to retain its quality, a minimum enrolment is needed - if only to ensure the replacement of teachers and researchers. Demographic challenges lie ahead for the EHEA. The population is decreasing and ageing, and participation in higher education can be expected to stagnate or even decline in the medium term.

With regard to the general population trend in the EHEA, the situation is clear. The European population is not achieving the minimum birth rate needed to reproduce itself and will decrease over the next 50 years (Mizikaci \& Baumgartl 2007). The population pyramid is rapidly inversing, with an ever smaller proportion of 18-24 years olds and an ever greater proportion of people above 50 (Klemenic \& Fried 2007). Given this demographic development alone, the potential number of students in higher education can be expected to decline. But this general picture has to be qualified somewhat. Social factors also play a role in enrolment rates (see below) and the number of pupils completing secondary education. Gender and age differences also define participation in higher education in general and in specific sectors of higher education in particular (full-time vs. part-time, humanities vs. sciences, etc.). This is why, generally speaking, participation in higher education in the EHEA is still expanding (European Commission (EC) 2007). In academ ically oriented programmes at ISCED level $5 \mathrm{~A}^{1}$, the number of students is increasing. In vocationally or practically oriented programmes (ISCED level $5 B$ ) participation rates are stable or slightly decreasing. At ISCED level 6 (advanced research programmes) enrolment is strongly increasing but account for only a small part of the students in higher education (only $2.9 \%$ of all students in the EU) (EC 2007: 38 ). 
In short, overall student numbers are growing. In the European Union, the higher education participation rate in the 18-19 year-old age group now amounts to $11 \%$ on average, but there is large variation between countries from less than $5 \%$ in Lithuania to more than $18 \%$ in Finland (EC 2007: 41).

Women are slightly higher in number at ISCED levels $5 \mathrm{~A}$ and $5 \mathrm{~B}$ but are underrepresented at level 6 (EC 2007: 44). However, this overall figure masks large differences regarding the fields of study. If we look at the EU only, the fields lar education, health, and the of study populated by a clear majority of women are education, health, and the humanities and arts, all of which have a student population of more than two-thirds women. By contrast, men are in the majority in science, mathematics and computing, and construction (EC 2007: 48)

This brings us to the issue of the number of students in science and technology, one of the benchmarks in the Lisbon Process. Among the five education benchmarks set, the increase in the number of mathematics, science, and technology (MST) graduates by $15 \%$ by 2010 is the only one that is likely to be met (EC 2005). In the $\mathrm{EU}$, the proportion of enrolments in science and technology is about a quarter at ISCED Levels 5A and 5B, while it is more than a third at ISCED level 6 (EC 2007: 52). A somewhat different picture emerges for the number of graduates. Broken down into fields of study, the social sciences, business, and law account for the largest numbers, that is, about $30 \%$ to $40 \%$ of all graduates. Generally speaking, the number of graduates in science, mathematics, and computing is around $10 \%$ of al graduates, and in engineering, manufacturing, and construction between $10 \%$ and 15\% (EC 2007: 165). At ISCED level 6, however, science, mathematics, and 15\% (EC 2007: 165). At ISCED leve extent, also engineering, manufacturing, and construction produce a proportionally large number of doctoral graduates (EC 2007: 166) Although the Lisbon benchmark might be met by 2010 , it must be admitted that between 1998 and 2004, only a slight increase can be observed. Moreover, the between 1998 and 2004, only a slight increase can be observed. Mut the gender benchmark also states that the gender imbalance should decrease, but the gender gap

As noted above, the age structure of the population in Europe is changing Those above 65 years are expected to account for one-third of the population by 2050 , and the age groups between $15-49$ will decrease from over $50 \%$ in 1950 to $38 \%$ in 2050 (Zaidi 2008). In other words, one can expect not only a decrease in the student population but also an increase in the age of the students and the teachers. The age structure of the students in higher education in Europe currently shows a considerable amount of variation, with participation clearly the highest in the median age differs between European countries by no less than 10 years of age (EC 2007: 58). In general, part-time students and those in short vocational programmes (groups that overlap to some extent) are older. Moreover, part-time students take much more time to finish their studies, more than would be expected as a result of their studying part-time. In the EU, they are on average 6 years older (EC 2007: 11).

It can be expected, with the ageing of the population, that fewer young people will enter higher education, and, conversely, that more older people will want to study - or study again - in higher education. The expectations and needs of the students as regards their studies and the study environment can, therefore, also be expected to change. However, participation in lifelong learning, defined a participation of the 25-64 age group, is almost stable at somewhat less thaned as (EC 2005: 18). The group of lifelong learners consists primarily of people who have already had higher education. Here too, then, a participation gap can be discerned.

\section{TECHNOLOGY AS A DRIVING FORCE}

The network society could not have developed without ICT, which has become an important part of social life since the 1960s. The existence of ICT and the level of use of its instruments strongly influence the development of the network society. Inversely, too, the network society contributes to the development and dissemination of ICT. In other words, there is a dialectical relationship between the network society and ICT.

Generally speaking, Europe's position regarding ICT is still one of the most privileged although the availability and the use of ICT are expanding throughout the world. Of the 29 countries with the highest average ICT value in the world 17 are Bologna countries (table 1). The highest scores for ICT are located in Western Europe, the lowest in the south and even more in Eastern Europe. Nevertheless, in all of the countries, the distribution and use of ICT equipment is expanding. The ICT growth of the weaker ICT inclined Bologna countries is slower than in the stronger ones. One might expect that it will take some time for them to catch up.

Table 1. Average values for several ICT indices in Bologna and other countries

\begin{tabular}{|c|c|c|c|}
\hline Country categories & Networks index ${ }^{2}$ & Intensity index $x^{3}$ & growth rate \\
\hline Highest ICT value ( 29 countries) & 432.1 & 451.80 & 54.65 \\
\hline - of which 17 Bologna countries * & 481.4 & 428.49 & 51.92 \\
\hline Medium ICT value ( 28 countries) & 229.6 & 229.66 & 56.17 \\
\hline - of which 13 Bologna countries * & 240.9 & 220.92 & 58.44 \\
\hline Lowest ICT value ( 63 countries) & 103.6 & 100.65 & 49.19 \\
\hline - of which 12 Bologna countries* & 123.7 & 88.15 & 55.46 \\
\hline
\end{tabular}

The rapid development of ICT has had a tremendous impact on the development of globalization and internationalization. In universities, for instance, because of ICT, faculty mobility, recruitment of international students and researchers, the transfer of knowledge, and research collaboration have become much easier than it ever was before.

Not only have globalization and internationalization changed under the influence of ICT but so, too, have the kind and the organization of work. Observations made in Australia and Canada, two countries that are among the highest ICT developed nations, might be instructive as regards the future possible changes in the economy and the labour organization of the Bologna countries with a lower ICT level (Crow \& Longford 2000; Curtain 2000). On the one hand, ICT boosted production and created new types of work but, on the other, it also made thousands of blue and white collar 
workers redundant (switched-off labour) The type of the preferred human capital changed. Well-educated and trained workers (self-employable labour) became necessary for the functioning of ICT, and less-skilled persons (generic labour) were threatened with dismissal. The character of work, too, underwent the influence of digitalization. On the one hand, this 'prescriptive technology' creates a type of work where the worker only can follow the prescribed procedures of the work that has to be done. On the other hand, it creates more than before the possibility for non-standard forms of employment and part-time work because a large number of complicated actions can be performed by technology. Within this context a group of flexiworkers has been created. These non-standard employed people will face 'the varying hours of work, multiple employer, open-ended contract, limited benefits, uncertain protection, and a variable place of work' (Curtain 2000: 8). It is also expected that telework, home-based work, and consulting will grow.

Turning to the EU, a recent CEDEFOP report (2008: 46) calculated that ICT certainly has influenced the employment patterns in the EU but to varying degrees in different economic sectors. Employment will decline in agriculture, fishery, manufacturing, and also for clerks Nevertheless, the number of people in other occupations will grow in numbers: technicians, professionals, and managers. Between 2006 and 2015, about 12.5 million highly qualified jobs (ISCED levels 5 and 6) will be added to the work force. The demand for skilled workers will also grow along with the demand for unskilled workers, which seems to support the development of a society divided in function of education. Nevertheless, we should be cautious about generalizing the picture for all the countries of the EHEA.

Universities play and will continue to play an important role in the training of these managers and professionals (see below). Moreover, they build and will continue to build all kinds of networks within their organizations and with other institutions, nationally and internationally. ICT as an instrument for managing universities, conducting research, and stimulating learning will increase in importance. Universities have established computer systems to support networks between lecturers, students, managers, researchers, governors, and other stakeholders not only for building networks but also for the evaluation of the work of lecturers and researchers. Similar links are being built between universities and their members, nationally and internationally, a process that is being encouraged by governments and the EU (e.g. the recently established EIT). And although GATS was not favoured by many universities, more and more of them will establish branch universities or campuses (Altbach \& Knight 2007) outside Europe in order to make money. Whether this process will continue in the future is uncertain because of the changing opportunities (Healey 2008). Virtual universities (GuriRosenblit, 2001), already present, might grow in number.

\section{INEQUALITY AND EMANCIPATION}

In the network society, access to the networks is a minimum condition for the economic, political, and social membership of a society. Therefore, "control over access becomes a crucial mechanism of power and domination, and the divide between the included and the excluded constitutes a line of stratification with serious political and material consequences' (Barney 2006: 31). In this way, political and material inequalities are to be expected. However, the network socie ty at the same time holds promise for breaking down the old lines of stratification. A network has dominant actors (nodes) and values, but they do not really have a centre or a fixed hierarchy. This means that other nodes can bypass the dominant nodes by increasing their own importance in the network. Moreover, actors can build an alternative network based on other values, and compete communicative ly with other networks to disseminate their alternative cultural codes. Thus, social change is possible in the network society.

ICT and Economic Inequality

In this section, we will test the hypothesis that the use of equipment for modern networking diminishes the inequality of economic remuneration. To this end, we use several indices. The networks index (NI) (see also Section 3 ) gives a rough indication of some of the basic instruments for building a modern network society $y^{5}$. The intensity index (II) gives a picture of the use of the Internet and the telephone for international contact. A global picture of ICT use is given by the ICT opportunity index (ICT-OI), and average annual growth refers to the growth of ICT-OI values between 2001 and 2005 .

Table 2. The means and standard deviations of NI, II, ICT-OI, and the growth rates in different Bologna areas

\begin{tabular}{|l|l|l|l|l|l|l|l|l|}
\hline & \multicolumn{2}{|l|}{$\begin{array}{l}\text { Networks index } \\
\text { (NI) } 2007\end{array}$} & \multicolumn{2}{l|}{$\begin{array}{l}\text { Intensity index } \\
\text { (11) } 2007\end{array}$} & \multicolumn{2}{l|}{ ICT-OI value } & \multicolumn{2}{l|}{$\begin{array}{l}\text { Average annual } \\
\text { growth rate 200 1- } \\
\text { 2005 }\end{array}$} \\
\cline { 2 - 9 } & Mean & $S D$ & Mean & $S D$ & Mean & $S D$ & Mean & $S D$ \\
\hline Bologna & 304.8 & 171.0 & 267.0 & 159.9 & 220.2 & 97.7 & 54.95 & 16.1 \\
\hline West $^{6}$ & 463.9 & 125.6 & 411.3 & 112.6 & 306.6 & 58.9 & 48.86 & 11.0 \\
\hline East $^{7}$ & 185.4 & 76.0 & 158.8 & 87.6 & 155.3 & 56.3 & 59.52 & 17.9 \\
\hline NW Europe & 501.1 & 106.5 & 431.8 & 78.9 & 326.1 & 39.2 & 51.83 & 10.6 \\
\hline
\end{tabular}

Source: ITU, 2007 (our own calculations)

Table 3. The Gini index and the means and standard deviations of HDI and GDP of different Bologna areas

\begin{tabular}{|c|c|c|c|c|c|c|}
\hline \multirow[t]{2}{*}{ Area } & \multicolumn{2}{|l|}{ Gini } & \multicolumn{2}{|c|}{ HDI 2004" } & \multicolumn{2}{|c|}{ GDP $2004(\$)$} \\
\hline & $\begin{array}{l}\text { Lowest } \\
\text { inequality }\end{array}$ & $\begin{array}{l}\text { Highest } \\
\text { inequal ity }\end{array}$ & Mean & $S D$ & Mean & $S D$ \\
\hline Bologna & 23 & 43.6 & $0.873^{3}$ & 0.076 & 20.326 & 13.569 \\
\hline West ${ }^{6}$ & 23 & 38.0 & $0.943^{\prime \prime}$ & 0.014 & $30,201^{111}$ & 4.879 \\
\hline East $^{7}$ & 24 & 43.6 & 0.819 & 0.057 & 10,869 & 6.054 \\
\hline NW Europe ${ }^{x}$ & 23 & 34.0 & $0.947^{\prime 2}$ & 0.009 & $31,769^{111}$ & 3,526 \\
\hline
\end{tabular}

Watkins et al. 2006 (our own calculations) 
Inequality is measured, first, within countries by using the Gini coefficient as an indicator of the dispersion of the income in a country: the higher the coefficient, the more the inequality between the incomes in a country, the lower the coefficient the more equality. Second, inequality between countries is indicated by the Human Development Index (HDI) (between 0 and 1) and the GDP ${ }^{11}$.

There is a great deal of inequality among the Bologna countries as far as the equipment for modern networking is concerned. The lowest NI score is $\mathbf{6 9 . 6}$ (Armenia) and the highest is 616.5 (Denmark). The average score is 304.8 with several lines of difference between countries. There is a large difference between the western countries (463.9) and the eastern countries (185.4). The most privileged situation can be found in NW Europe (501.1). The same pattern is found for the II and ICT-OI. Western countries have more opportunities for ICT than do the eastern ones. These countries not only score the highest on the NI, II, and ICTOI but also show the highest average GDP $(\$ 31,769)$ and the highest average score on HDI (0.947). Moreover, among these countries, we find countries with small income inequality among the citizens. The Gini score (34 in comparison with 43.6 and 38 ) for the country with the highest income inequality is lower than in all other Bologna areas of Table 2. The lowest average score for HDI (0.819) and GDP $(\$ 10,869)$ is found in the eastern countries. Although the Bologna countries have many similar targets for higher education, the resources available to achieve these targets are distributed very unequally between west and east.

Table 4. Correlation between NI, II, ICT-OI, growth, the Gini index, and the HDI of different Bologna areas

\begin{tabular}{|l|c|c|c|c|}
\hline & $\begin{array}{c}\text { Bologna } \\
\text { countries }\end{array}$ & West $^{6}$ & East $^{{ }^{7}}$ & NW Europe $^{8}$ \\
\hline NI x Gini & $-0.474^{*}$ & $-0.515^{*}$ & -0.365 & -0.321 \\
\hline NI x HDI & $0.855^{*}$ & $0.543^{*}$ & $0.845^{*}$ & 0.008 \\
\hline II x Gini & $-0.431^{*}$ & -0.418 & -0.272 & -0.539 \\
\hline II x HDI & $0.857^{*}$ & $0.564^{*}$ & $0.790^{*}$ & 0.291 \\
\hline ICT-OI x Gini & $-0.476^{*}$ & $-0.574^{*}$ & -0.311 & -0.461 \\
\hline ICT-OI x HDI & $0.902^{*}$ & $0.684^{*}$ & $0.866^{*}$ & 0.229 \\
\hline $\begin{array}{l}\text { Growth ICT-OI x } \\
\text { Gini }\end{array}$ & 0.313 & 0.089 & 0.286 & 0.426 \\
\hline $\begin{array}{l}\text { Growth ICT-OI x } \\
\text { HDl }\end{array}$ & $-0.328^{*}$ & 0.291 & -0.097 & 0.038 \\
\hline Gini $x$ HDI & $-0.528^{*}$ & $-0.583^{*}$ & $-0.522^{*}$ & -0.216 \\
\hline * $\leq .05$
\end{tabular}

$\mathrm{p} \leq .05$

In the developed countries, it may be expected that there would be a strong relationship between $\mathrm{HDI}$ and the index measuring the availability of network instruments (NI). The data of the Bologna countries support this hypothesis $\left(r=.855^{*}\right)$, which also holds separately for the western $\left(r=.543^{*}\right)$ and the eastern countries $\left(r=.845^{*}\right)$. Table 4 also shows that it is possible to find more equipment for modern networking in countries where people enjoy more income equality $\left(r=-.47^{*}\right)$. If we take the groups of countries separately, the calculated relationships are only significant in the west. This brings us to the hypothesis that countries with a high level of development (HDI) and with a relatively narrow span of income inequalities (Gini) may also grow to a higher ICT-OI value than they have at this moment. Thus, it can be expected in the future that countries with an increasing level of human development and a diminishing distance between income levels may acquire more instruments for modern networking.

A similar pattern is found in the relations between II and ICT-OI, on the one hand, and the Gini and the HDI on the other. The less the income inequality, the greater the intensity of the use of ICT equipment $\left(r=-0.431^{*}\right)$ and the higher the ICT-OI index $\left(r=-0.476^{*}\right)$. After checking for the difference between west and east, we see that this relationship only holds in the west for ICT-OI $\left(r=-0.574^{*}\right)$. Just like above, the higher the HDI of a country, the more ICT equipment is used intensively $\left(\mathrm{r}=0.857^{*}\right)$ and the higher the score for ICT-OI $\left(0.902^{*}\right)$. This holds not only for all the Bologna countries but also for the eastern and western Bologna countries separately. We also see that there is a weak insignificant relationship between the growth of ICT opportunities and increasing income inequality in all the Bologna countries $(r=0.313)$. A weak relationship can also be found between increasing ICT opportunity and diminishing HDI $\left(r=-0.328^{*}\right)$. This seems to suggest that the growth in ICT opportunities is greater when the HDI decreases in the Bologna countries. However, this does not hold any longer when the west and the east are analysed separately.

Table 4 shows that the availability and the use of modern network equipment in the Bologna countries depends strongly on the development of the society as measured by the HDI (respectively $r=0.855^{*}, r=0.857^{*} ; r=0.902^{*}$ ). This still holds when we control for income inequality (Gini index) (respectively partial $r=.806^{*}$, $\left.\mathrm{r}=0.817^{*}, \mathrm{r}=0.869^{*}\right)$. On the other hand, the relationship between the Gini index and NI (partial $r=-0.071$ ), II (partial $r=-0.016$ ), and ITC-OI (partial $=-0.039$ ) disappears when we control for the HDI. ICT opportunities seem to be much more influen ced by the development of society (HDI) than by the inequality of income (Gini).

\section{Migration and Mobility}

The information-oriented society is looking for skilled workers, and migration is an important process in obtaining them, so well-trained people look for opportunities in societies where the information structure is richer and where their expectations may be fulfilled. Migration is very different from country to country. The lowest immigration figure is $0.6 \%$ (Romania) of the population in a country, and the highest is $37.4 \%$ (Luxembourg). We checked whether the HDI and the Gini index could be linked with these migration patterns in the Bologna countries (based on data of UN, 2006; our own calculations). We could find no significant relations hip between the HDI and the Gini index, on the one hand, and the stock of migrants as a proportion of the total population in the different Bologna countries, on the other. Still, there was a growing positive correlation between the migrant figures of 1995 $\left(r=.37^{*}\right), 2000\left(r=.528^{*}\right)$, and $2005\left(r=.628^{*}\right)$ and the GDP of 2004: the higher the GDP of a country, the higher the proportion of migrants in that country. In other words, rich countries are more attractive for migrants. 
Most of the migrants in 1960 in European countries were men $(52 \%)$ (UN, 2006). Since the $1990 \mathrm{~s}$, this pattern has changed. At present, the largest proportion of migrants in Europe is composed of women ( $53.4 \%$ in 2005). More than before, of migrants in Europe is composed of wition in other countries. However, contrary women are trying to improve their position in other countries. However, contrary to the general pattern of migration, in 2005 there is a weak indication that the proportion of women among migrants is higher in countries with a lower GDP $(r=-.242)$.

As countries need highly skilled workers more than previously to organize the network society, they try to influence the kind of migrants they want. Most develop a migration policy. Of 36 Bologna countries, $39 \%$ have a policy to raise the a migration and and $53 \%$ try to maintain proportion of highly skilled workers among the migras the level of this kind of migration. A policy to increase this number is found in a larger proportion of the NW Bologna $(58 \%)$ countries than in the others $(29 \%)$ (UN 2006; our own calculations).

Turning from migration to temporary mobility and particularly to the training received by youngsters in other countries than where they used to live, we see that the number of EU HE students studying in a foreign European country ${ }^{12}$ is low:

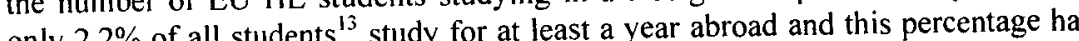
not increased over the years (EC 2007: 129). And although there are more female than male students, a larger proportion of male students are studying abroad. Notwithstanding the EU's efforts to support mobility of HE students and networking Notwithstanding the EU have participated in the ERASMUS programme), here, too, the socioeconomic divide of the society is visible. Students hailing from better off families participate more in the programme than do the others. Moreover, the participation of students more in the progan in with parents having en rountries also belong students living in other families, and students of the richer countries also belong more to the richer socioeconomic categories than do the students coming from the poorer countries. Although this kind of networking is very much appreciaripants, ultimately it does not seem to guarantee salary gains or higher level jobs (Otero 2008: 141)

\section{The Gender Gap}

The network society, supported by ICT, not only reproduces the socioeconomic divide in our society but also the gender divide even when this society might change the power relations and offer local democracy and electronically stimulated participation and communication (see $\$ 1$ ). One of the reasons is that ICT applications attract fewer women than men. Most of the Internet users in 2002 were male. The highest proportion of female Internet users $(48 \%)$ could be found in Sweden (ITU 2007). In the EU, 28\% of the females and 33\% males (16-74 year in Sweden (ITU 2007). old) use the Internet for interaction with public authorities (Eurostat 2008). Networking by ICT does not put women in a privileged position, but the network society does offer other opportunities for emancipation. One of them is gender mainstreaming, which can be defined as 'a process that seeks to advance gender equality by revising all mainstream policy arenas' (Walby 2005).

THE EHEA IN THE CONTEXT OF THE NETWORK SOCIETY

The informational economy needs 'self-programmable labour'. In other words, 'brains' are the most important 'raw material' of the informational economy. In the previous sections, we showed that the education and training of the 'brains' capable of functioning in the network society is crisscrossed by a number of demographic, technological, and social developments. Higher education in the EHEA is being confronted with these challenges. Moreover, the EHEA itself can be regarded as an expression of the network society. Castells refers to the European Union as a network state (Castells 1998). The EU is a way of cooperation between states. The EU is a transnational space in which actors on different policy levels interact in a structure that can be characterized as a network. In higher education, we have witnessed the growth of this new polity and its transnational consequences. In 30 years time, action programmes have been established, often against the policy of some of the Member States, which have had a clear impact on the mobility of students and staff, cooperation in networks of institutions, and the learning to know each others' language and culture. These are domains that are not central to the Member States' educational competence but that, nevertheless, are crucial in the light of a developing network society. Higher education is viewed in the programmes of the EU as an economic factor in the competition on the free market. The neo-liberal idea of removing barriers to the free trade of capital, goods, services, and people is thus penetrating higher education (Verhoeven 2006). The role of the $\mathrm{EU}$ in higher education is not replacing the policies of the Member States but is regulating a competitive market through legal initiatives and stimulatory activities.

However, the borders of what formally belongs to the EU and what, strictly speaking, does not belong to it, are permeable (De Wit 2003). Initiatives and programmes of the EU often are not restricted to EU member states, and actors and processes outside the EU are equally part of the 'networks' that constitute the European polity. Therefore, we would do better to speak of 'Europe' as the new, most relevant polity. This is true especially for higher education, and the Bologna Process is a prime example. The EU and the Bologna Process are more closely linked to each other than would appear at first sight (De Wit 2008). The EU finances the follow-up of the Bologna Process and is part of the follow-up group that is monitoring the Bologna reforms. Moreover, the EU funds transnational projects in order to create 'synergies' between the Bologna Process and the EU policy on higher education. The EU also provides the methods and instruments used to create the EHEA, that is, the method of open coordination and instruments like the mobility programmes, the diploma supplement, and the ECTS. Finally, the goals of the Bologna Process are largely the same as the goals of EU cooperation in higher education.

The aim of creating a European Higher Education Area is, in fact, situated in the market environment that is being created on a European scale for higher education 
(and in a similar way, for research, in the European Research Area). In this market environment, a paradox can be discerned. On the one hand, a market and, hence, competition is created. On the other, it is expected that this competition is met by cooperating on projects, in networks and consortia, etc. Moreover, the goal is increasingly to present European benchmarks alongside common standards and good practices. This is true also for the EHEA, where 'open coordination' is intended to tune policies without taking coordinating, hierarchical decisions.

This has several consequences for higher education. To begin with, higher education institutions are being confronted with market processes both in their own functioning and in their relationship with other organizations. The relationship with the government, too, can be characterized by the introduction of market operations, deregulation, liberalization, and steering at a distance.

This means that the barrier between higher education and 'external interests' is breaking down (Neave 2002). The demands of the techno-economic system and particularly of the predicted demands of the labour market become more directive. In this new normative view, higher education is expected to 'deliver' flexible, mobile, communicative, and lifelong-learning individuals, to aim at individual students as consumers and target groups, and to offer tailored education, for example, on local campuses or through distance education. In this sense, higher education institutions become enterprises that 'produce' education or human capital, and the students (and parents) become 'consumers'.

Part of the training now still provided by institutions of higher education might be taken over by the growing number of corporate universities (Mazarol \& Soutar 2001: 162). Business and industry are important partners for universities in building networks, but they might also be very important competitors. In spite of the research tradition at universities, the largest amount of money for research is being spent by private industry, a development very often supported by the state. A Delphi study of European higher education experts showed that most of them fear that more than $60 \%$ of basic research would be conducted outside institutions of higher education in 2020 in Europe (Huisman et al., 2005: 33).

Furthermore, economic, and educational goals seem to be becoming ever more intertwined. Higher education institutions increasingly have to compete with each other for financing and have to enter into contractual relations with third parties. This means that they are being increasingly confronted with the diverging interests of third parties and are being asked to show their accountability and quality management.

The market-like processes might also lead to institutions of higher education functioning more like enterprises. In this sense, they might become more like network enterprises, that is, organizationally flexible, in order to be able to adapt to their environment and the variable geography of nodes in the network, using ICT to coordinate tasks, define specific goals, and manage the complexity of the network. Even in uncertain circumstances, a network enterprise is able to generate and process knowledge efficiently and to make use of it flexibly. Its success depends on linking decentralized implementation to integrated decision making. In this sense, universities have been defined as entrepreneurial (Clark 1998) or, we might say, network universities.
For institutions of higher education, the idea of functioning as a network runs counter to its predominant organizational form, that is, a professional bureaucracy. They consist of loosely coupled parts that cannot easily be moved in the same direction or adapted in the same way to a changing environment. But this is changing. New management forms are finding their way into higher education leading to the diminishing importance of collegial decision making and to the streamlining and professionalization of institutional management (Amaral et al. 2003).

Institutions of higher education have, of course, a long tradition of formal networks of disciplines and professions and informal networks of academics (Dil 1997). In a network society, however, these traditional networks are integrated to enhance the adaptive capacity of the organization, or, in other words, the diverging units of the differentiated structure can (thanks to ICT) be coordinated. These new networks follow less the traditional disciplinary dividing lines and more the path of interdisciplinary and multidisciplinary cooperation (Salmi 2001) not only as a reorganization of traditional units (e.g. departments) but also as a new set of cognitive and social practices related to 'Mode 2 of knowledge production' (Gibbons 1999).

We must keep in mind that a higher-education market is at most a quasi-market. Most consumers do not 'pay' for the product themselves; most 'producers' obta in their basic financing from the government; and the 'market' is not free but regulated. Nevertheless, on this quasi-market, commercializing research results, for example, can be used as a means to increase income, but this can also endanger the autonomy of the researcher. Tenure, too, is no longer guaranteed (Weber 1999). In other words, by becoming involved in 'academic capitalism' (Slaughter \& Leslie 1999), institutions of higher education risk losing that which makes them an institution of higher education.

\section{CONCLUSIONS AND REFLECTIONS}

The network logic is penetrating the entire social structure and, hence, also higher education. Nevertheless, structure is not a one-way cause of action. That is, we must also look at how actors deal with networks, how they use them and interpret them. For example, linking computers through the Internet is one thing, having an appropriate cultural and academic setting in higher education in which the Internet is used to introduce students to the Information Age is quite another (Castells 2004).

It might be true that new social relationships are developing, but old associations like social classes have not disappeared (Halcli \& Webster 2000). We have shown above that 'old' divides, based on gender, age, wealth, skills, etc. are still operative in European societies. This has important consequences for institutions of higher education and for higher-education policy.

The population of Europe and the young population in particular is shrinking. This will lead to fewer students in higher education unless older age groups participate more in higher education or unless immigration compensates for the loss in enrolment. The latter is not a certainty (Mizikaci \& Baumgartl 2007). 
Moreover, it is not clear whether higher education in the EHEA is ready to accommodate a growing body of international students and staff because of the language being used (the language proficiency of teachers and students, the availability of information in different languages, etc.), to the content of the curricula, to accommodation for mobile students, and so on. Regarding the older students, we have seen that the age structure of the student population is diverse but that it still consists mostly of young people and that lifelong learning is hardly growing. In other words, if the network society requires highly qualified knowledge workers and knowledge producers, there is no guarantee that the demographic challenge can be met. The consequence might be a decreasing number of students and shortages of graduates on the labour market. We could also face an excess supply of higher education (Klemencic \& Fried 2007), at least in some regions. Issues of brain drain and brain gain will come more to the fore. In order to attract foreign and non-traditional students (e.g. minority students), quality as well as innovation might become an important issue. If the EHEA could show that it offers high quality education and that it takes account of new insights in learning, of the needs and expectations of non-traditional students, of new demands regarding skilled workers (communication skills, ICT skills) etc., it could become an area of interest for students from outside the EHEA. The Trends V report reaches a similar conclusion (Crosier et al., 2007).

The number of graduates in mathematics, science, and technology is increasing, for a large part as a result of growing female participation. More in general, IC availability and use are growing although there are important differences within the EHEA. ICT availability and use are high in Western Europe but much lower in South and Eastern Europe. Moreover, there are inequalities amongst the Bologna countries with regard to equipment for modern networking. Again West and East are on opposite sides. The same goes for the standard of living. Although the Bologna countries have similar targets with regard to the EHEA, the resources available for achieving these targets are clearly unevenly distributed. The goal is to create one area for higher education, but there seem to be different areas within the EHEA. It seems important to increase the development of societies and diminish the distance between income levels because this enhances the availability and use of ICT and networking. However, societies seem to reach a saturation point with regard to the relation between wealth and ICT: at a certain level of wealth, other factors come into play, hence the importance of targeted policies, for instance to promote science and technology in education, but also in research as with the EIT.

Social and cultural factors are still important in the network society. For instance, new forms of communication strengthen existing patterns of inequality because the wealthy and educated are far more likely to use them. Along the lines of education, skilled work and unskilled work are divided and lead to divisions in the kind of work, the organization of work, etc. In the present context, the network society reproduces the socioeconomic divide.

Institutions of higher education educate the national, European, and global 'elite' that will play a central role in the network society. But the mission of higher education cannot, and should not, be limited to that. With high and increasing participation rates in higher education, they should also offer opportunities for all, so that everyone can enjoy the advantages of the network society. These institutions should, in other words, make students capable and apt for this new society and provide them with appropriate values and social skills (Salmi 2001) Mobility is one of the key means, but this means that teachers must not only provide students with information but also be 'animators and commentators in charge of giving context and in-depth understanding of an area' (Weber 1999: 10).

If the mission of higher education should be to provide opportunities for all, this does not entail that each institution of higher education should provide the same opportunities. The student body is diversified and so there could well be a diversity in institutions catering for different target groups of students, taking into account their specific characteristics and educating them through diverse pathways for the challenges of the network society.

At the same time, institutions of higher education must remain a place where a critical view on social developments is possible. 'There must be things the university will not do no matter how much money is offered, for example, permitting donors to select faculty. Conversely, there must be "useless" things it insists upon doing, for example, cross-subsidizing the teaching of classics and philosophy because it is an institution committed to cultivation and transmission of a cultural heritage as well as to economic progress' (Clark 2004: 358). One of the main challenges in furthering the EHEA, therefore, will be to make progress with the implementation of its goals while ensuring that this implementation succeeds in achieving the goals for all.

\section{NOTES}

ISCED is the International Standard Classification of Education, a classification that combine levels of education with orientation (general, vocational, or pre-vocational) and destination (education or labour market). For higher education, three levels are distinguished: 5A (academic (education or labour market). For higher education, three levels are distinguished: $5 \mathrm{~A}$ (academic
programmes), 5B (vocational programmes), and 6 (advanced research programmes, i.e., PhD programmes).

2 "Network index: fixed telephone lines per 100 inhabitants, mobile cellular subscribers per 100 inhabitants, and international internet bandwidth (kbps per inhabitant)." (ITU 2007)

"Intensity index: total broadband internet subscribers per 100 inhabitants, international outgoing telephone traffic (minutes) per capita." (ITU 2007)

4 "The average annual growth rate (200I-2005) refers to the growth of ICT-OI values between 2001 and 2005." (ITU 2007)

5 a the following figures are based on information collected from 43 members of the Bologna Process. No information was available for Andorra, The Holy See, Liechtenstein, or Montenegro.

No information was available for Andorra, The Holy See, Liechtenstein, or Montenegro.
This area is composed of all of the countries located on the West side of the line Finland, Denmark, This area is composed of all of the count

7 This area is composed of all the countries that do not belong to the group listed in footnote 7

* This area is composed of 12 countries: the first six EEC countries and those countries located northwest of them

Because of Luxembourg's very high GDP, a correction for the calculation of HDI was applied for Luxembourg.

10 Because of Luxembourg's very high GDP, Luxembourg was excluded from the calculations.

11 The Human Development Index is 'measured by life expectancy at birth; knowledge, as measured by the adult literacy rate and the combined gross enrolment ratio for primary, secondary and tertiary 
schools; and a decent standard of living. as measured by gross domestic product GDP per capita in purchasing power parity (PPP) US dollars.' The gross domestic product per capita (GDP) is expressed in purchasing power parity US dollars, but we should not forget that GDP is also an indicator of the HDI (Watkins et al. 2006: 276)

12 In a country of the $\mathrm{EU}$, a candidate country, or an EFTA/EEA member country.

Students from Cyprus, Iceland, and Liechtenstein are in a special position in that the provision of higher education in their country is limited, so they very often study abroad.

\section{REFERENCES}

Altbach, P. G. \& J. Knight (2007) 'The internationalisation of higher education: motivations and realities, Journal of Studies in International Education, 11 (3/4) pp. 290-305.

Amaral, A.. O. Fulton. \& I.M. Larsen (2003) 'A managerial revolution' in: Amaral, A., V. L. Meek. \& I.M. Larsen (eds) The higher edication managerial revolution? Dordrecht/Boston/London Kluwer Academic Publishers pp. 275-296.

Barney, D. (2006) The Nenwork Socieny Cambridge: Polity.

Castells, M. (1993) 'The University System: Engine of Development in the New World Econony,' in: Ransom, A., S-M. Khoo \& V. Selveratnam (eds.) Improving Higher Education in Developing Countries. Washington D.C. World Bank pp. 65-80

Castells. M. (1996) The Rise of the Nenvork Society. The Information Age: Economy, Society and Culture. I'olume I. Oxford: Blackwell Publishers.

Castells, M. (1997) The Pover of Identity. The Information Age: Economy, Society and Culture. Volume 2. Oxford: Blackwell Publishers.

Castells, M. (1998) End of Millenmum. The Information Age: Economy, Society and Culture. Volume 3. Oxford: Blackwell Publisher.

Castells, M. (2000a) 'Materials for an exploratory theory of the network society', British Journal of Sociology, 51 (1) pp. 5-24

Castells, M. (2000b) 'Information Technology and Global Capitalism,' in: Hutton, W. \& A. Giddens (eds) On the Edge: Living with Global Capitalism. London : Cape pp. 52-74

Castells, M. (2004) 'Informationalism, Networks, and the Network Society: A Theoretical Blueprint,' in Castells. M. ed The Nenvork Society. A Cross-culnural Perspective. Cheltenham, UK Northampton, MA, USA : Edward Elgar pp. 3-45.

CEDEFOP (2008) Future skills in Europe. medium term for costs. synthesis report. Luxembourg Office for official publications of the European Communities

ClA (2008) The World Factbook, retrieved on 31 March 2008 on hitps:/www.cia.gov/library/ publications/the-world-factbook/index.htm

Clark, B. R. (1998) Creating Entrepreneurial Universities. Organizational Pathiays of Transformation. Oxford: Pergamon/lAU Press.

Clark. B. R. (2004) 'The Consequences of European Integration for Higher Education,' Higher Education Policy, 17 pp. $355-370$

Crosier, D., L. Purser \& H. Smidt (2007) Trends I: Universities shaping the European Higher Education Area. Brussels: EUA.

Crow, B. \& G. Longford (2000) 'Digital restructuring: gender, class and citizenship in the information society in Canada, Citizenship Studies, 4 (2) pp. 207-230.

Curtain, R. (2000) Changes to the nature of work. Implications for the vocational education and training system. Report to NCIER. Kensington Park: National centre for vocational education research Ltd

De Wit, K. (2003) 'The Consequences of European Integration for Higher Education,' Higher Edication Policy: 16 (2) pp. 161-178

De Wit K. (2008) Universiteiten in Europa in de 21 e eeuw. Nenterken in een veranderende samenleving. Gent: Academia Press.
Dill, D. D. (1997) 'Effects of Competition on Diverse Institutional Contexts,' in: Peterson, M. W . D.D. Dill \& L.A. Mets (eds.) Planning and Management for a Changing Environment: A Handb ook on Redesigning Postsecondary Institutions. San Francisco: Jossey-Bass pp. 88-105.

European Commission (2005) Commission Staff Working Paper. Progress Towards the Lishon Objectives in Education and Training. Brussels: European Commission.

European Commission (2007) Key Data on Higher Education in Europe. Luxembourg: European Conmission

European Commission (2008) EUROSTAT. retrieved on 2 April 2008 on htp://epp.eurostatec europa.eu/portal $/$ page? pageid=1996,45323734\& dad=portal\& schema=PORTAL\& tion\&scrollto $=0$ :

Gibbons, M (1999) 'Changing Research Practices,' in: Brennan, J., J. Fedrowitz, M.T. Huber \& T. Shah (eds.) What Kind of Universit?? International Perspectives on Knowledge, Participation and Governance. Buckingham/Philadelphia : SHRE / Open University Press. pp. 23-35.

Guri-Rosenblit, S. (2001) 'Virtual universities: current models and future trends,' Higher Education in Europe, XXVI (4) pp. 487-499.

Halcli. H. \& F. Webster (2000) 'Inequality and Mobilization in The Information Age, ' 3 (1) pp. 67-81

Healey, N. M. (2008) 'Is higher education in really 'internationalising"?' Higher Education, 55 (3) pp. $333-355$

Huisman, J, P. Boezerooy A. Dima, M. Hoppe-Jeliazkova. A, Luyten-Lub, E. de Weert \& M van der Wende (2005) 'A brief report on the Delphi study' European higher education and research in 2020', in: Enders, J.. J. File. J. Huisman \& D. Westerheijden (eds) The European higher education and research landscaped 2020. Scenarios and strategic debates. Enschede : CHEPS pp. 25-60

and research landscaped 2020. Scenarios and strategic debates. Enschede: CHEPS pp. 25-60
ITU (2007) Measuring the Information Society 2007. ICT Opportunity Index and World

ITU (2007) Measuring the Information Society 2007. ICT Opportunity Index and World
Telecommunication//CT Indicators, retrieved on 17 March 2008 on http://www.itu.int//TUD/ict/publications/ict-oi/2007/index.html

Klemenic, M. \& J. Fried (2007) 'Demographic Challenges and Future of the Higher Education, International Higher Education 47 pp. 12-14

Lash, S. \& J. Urry (1994) Economies of Signs and Space. London: Sage.

Mazzarol, T \& G.N. Soutar (2001) The global market for higher education. Sustainable competitive strategies for the men Millenuim. Chellenhan (UK)/ Northampton (USA): Edward Ele VII + $200 \mathrm{pp}$

Mizikaci, F. \& B. Baumgartl (2007) 'Demographic Trends and Risks for European Higher Education,' International Higher Education $47 \mathrm{pp} .15-16$

Neave, G. (2002) 'On Stakeholders, Cheshire Cats and Seers: Changing visions of the University,' in Goedegebuure, L \& J. File (eds.) The Cheps Inangurals 2002. Enschede : Universiteit Twente pp. $8-27$.

Otero, M. S. (2008) 'The Socio-economic Background Of ERASMUS Students: A Trend Towards Wider Inclusion?' International Review' of Education, 54 pp. 135-154.

Salmi. J. (2001) 'Tertiary Education in the 21 st Century: Challenges and Opportunities' Higher Education Management, 13 (2) pp. 105-130

Slaughter, S. \& L. Leslie (1997) Academic Capitalism: Politics. Policies and the Entrepreneurial University. Baltimore: Johns Hopkins University Press.

UN Population Division (2006) World Migrant Stock: The 2005 Revision. Population Darabase, retrieved on 31 March 2008 at http://esa. un.org/migration/index.asp?panel=2

Verhoeven. J. C. (2006) 'Internationalization and commercialization of higher education in an era of globalization,' in: Zhang Hui (ed) Teacher Education. Education Policy, Innovation of Higher Education, Motivation and Evaluations of Students: A Comparative Approach. Shenyang : Liaoning University Press pp. 133-146.

Walby, S. (2005) 'Introduction: Comparative Gender Mainstreaming in a Global Era,' International Feminist Journal of Politics. 7 (4) pp. 453-470 
Watkins $K$ et al (2006) Human Development Report 2006. Beyond scarcity: Power, poverty and the global water crisis. New York: Palgrave Macmillan $422 \mathrm{pp}$.

Weber, L. E. (1999) 'Survey of the Main Challenges Facing Higher Education at the Millennium,' in: Hirsch, W. Z. \& L.E. Weber (eds.) Challenges Facing Higher Education at the Millennium. Oxford: Pergamon/IAU Press pp. 3-17

Zaida, A. (2008) Features and Challenges of Population Ageing: The European Perspective. Vienna: European Centre for social Welfare policy and research (Policy Brief March (I), retrieved on 3 April 2008 on http://www.euro.centre. org

\section{EUROPEAN HIGHER EDUCATION IN SEARCH OF INSTITUTIONAL ORDER ${ }^{1}$}

\author{
INTRODUCTION
}

European integration seems to be in full swing when it comes to higher education. This is not only visible in the ongoing national reform processes in higher education, but also in European level policy documents and reform proposals, aimed at stimulating the integration of European higher education. Consequently, a stocktaking and forward-looking project like the one in the framework of which this chapter is produced can be expected to look into the state of our theoretical and empirical understanding with respect to the European integration of higher education. Where are we regarding our understanding of the dynamics of the university as the core 'Knowledge Institution' in Europe? What do recent studies into European integration efforts of higher education tell us about the possible future developments of the 'European Higher Education Area'? What are the major concepts used in these studies and how do they contribute to our understanding of the possible new directions the Bologna process might take after 2010 ?

Especially since the signing of the Bologna Declaration in 1999 and the Lisbon 2000 summit higher education has become more important as a policy issue at the European as well as at the national level within the (larger) EU area. The growing importance of higher education in the various policy arenas in Europe has been accompanied by a slow but steady increase in research in higher education, with a special focus on the Bologna process seen as the core European integration process with respect to higher education. However, despite the growing number of studies focused on European integration of higher education, overall there are major knowledge gaps in the European policy debates on higher education (Olsen and Maassen 2007) and inconclusive, weak and ambiguous data are often used to legitimize strong conclusions concerning the need for urgent and radical reforms.

There are a number of excellent studies on the Europeanization of higher education (e.g. Corbett 2005; Witte 2006). However, studies on European integration and higher education have often suffered from what might be called 'doubleisolatedness'. Many studies have treated higher education as a sector isolated from the overall European integration processes. In addition, rarely analytical frameworks from general social sciences, and especially European studies have been used for studying European integration processes in higher education.

The starting point is that in order to improve our understanding of European integration in higher education first we have to strengthen our analytical frameworks, and second we have to carefully examine the empirical evidence used for 


\section{The European Higher Education Area:}

Perspectives on a Moving Target

Barbara M. Kehm

International Centre for Higher Education Research (INCHER-Kassel). University of Kassel, Germany

Jeroen Huisman

International Centre for Higher Education Management (ICHEM),

University of Bath, United Kingdom

\section{Bjørn Stensaker}

Norwegian Institute for Studies in Innovation, Research and Education (NIFU

STEP), Oslo, and Institute of Educational Research, University of Oslo, Norway

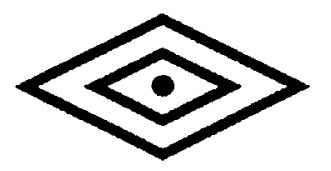


ISBN 978-90-8790-712-9 (paperback)

ISBN 978-90-8790-713-6 (hardback)

ISBN $978-90-8790-714-3$ (e-book)

Published by: Sense Publishers,

P.O. Box 21858, 3001 AW

Rotterdam, The Netherlands

http://www.sensepublishers.com

Printed on acid-free pape

\section{All Rights Reserved $\bigcirc 2009$ Sense Publishers}

No part of this work may be reproduced, stored in a retrieval system, or transmitted in any form or by any means, electronic, mechanical, photocopying, microfilming, recording or otherwise, without written permission from the Publisher, with the exception of any material supplied specifically for the purpose of being entered and executed on a computer system, for exclusive use by the purchaser of the work.
Foreword

Minister Frank Vandenbroucke

Bologna, Quo Vadis?

Jeroen Huisman, Bjorn Stensaker and Barbara M. Kehm

\section{Part I: Governance}

1. Institutional Autonomy 2010-2020. A Tale of Elan - Two Steps back to make one very Large Leap Forward

Guy Neave

2. The Relevance of Higher Education to Knowledge Society and Knowledge-Driven Economy: Education, Research and Innovation Jussi Välimaa

3. Economic Imperialism and The Ivory Tower: Some Reflections upon the Funding of Higher Education in the Ehea (2010-2020) Pedro Teixeira

4. Market Governance in Higher Education

Harry de Boer, Jürgen Enders and Ben Jongbloed

5. European Higher Education in Search of a New Legal Order Jan de Groof

\section{Part II: Quality}

6. The Changing Attractiveness of European Higher Education: Current Developments, Future Challenges, and Major Policy Issues Marek Kwiek

7. The Ingredients of Trust in European Higher Education Bjorn Stensaker and Ase Gornitzka

8. Quality, Equity and the Social Dimension: The Shift from the National to the European level

John Brennan, Rajani Naidoo and Kavita Patel 
9. The University Community in a European Community: Investigating the Notion of an Engaged University

David Watson and Paul Temple

\section{Part III: Mobility and Human Resources}

10. Student Mobility and Staff Mobility in the European Higher Education Area Beyond 2010

Ulrich Teichler

11. The Rationalization of Academic Work and Careers: Ongoing Transformations of the Profession and Policy Challenges

Julien Barrier and Christine Musselin

12. New Forms of Doctoral Education and Training in the

European Higher Education Area

Barbara M. Kehm

\section{Part IV: Diversity}

13. The Bologna Process Towards 2020: Institutional

Diversification or Convergence?

Jeroen Huisman

14. Features and Future of the Network Society: The Demographic Technological and Social Context of Higher Education Kurt De Wit and JefC. Verhoeven

15. European Higher Education in Search of Institutional Order Peter Maassen

\section{Part V: The External Dimension}

16. The External Dimension: Positioning the European Higher Education Area in the Global Higher Education World Simon Marginson

List of Authors

\section{FOREWORD}

BOLOGNA TODAY

In designing the future of the Bologna Process, we first should look at the outcomes and results produced thus far. An independent assessment has been asked for by the European ministers to clarify what has been really achieved and to what extent this has been done. Without anticipating the conclusions of the assessment, one can nevertheless already acknowledge the impressive achievements of the first ten years of the process. The vision that guided the gathering in Bologna in 1999 , was to have an integrated higher education area in Europe by 2010 , with transparent and readable higher education systems, trustworthy institutions and 